\title{
$+2 \mathrm{~L}$ \\ 204 \\ . $\mathrm{Ch} 4$ \\ L35
}

Larrèategui, José Dionisio

Descripciones de plantas 



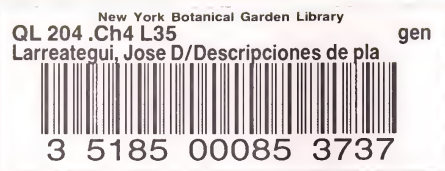




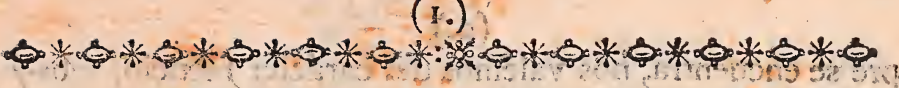

\section{DESCRIPCIONES DE PLANTAS.}

Discurso que en la abertura del estudio de Botánica de 1. de Junio de 95. pronunció en el Real Jardin de México el Br. D. Joseph Dionisio Larreátegui, Cursante de Medicina y Discipulo de esta Escuela, presidiéndolo su Maestro y Catedrático

\section{Vicente Cervántes.}

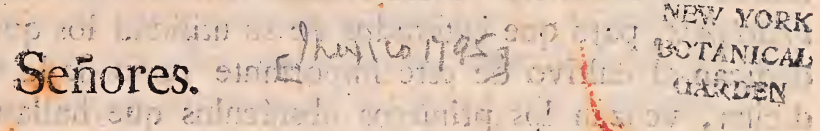

TNA de las principales cosas que han contribuido mas á los progresos de la Historia natural y que cederá siempre en beneficio de sus útiles trabajos, ha sido sin disputa la exâctitud y precision establecida últimamente en las descripciones de sus individuos, como nos las presentan en el dia muchos Sabios del primer órden en los tres dilatados reynos de la Naturaleza. Por ellas nós enteramos de todo el carácter natural del objeto descrito, separándolo por este-medio de los demas cuerpos análogos con quienes pudiera equivocarse. En el conjunto de signos naturales sobresale siempre la nota esencial, ó característica, si la tiene, recomendable por, subrevedad, y muy oportuna por lo mismo para fixarla en la memoria, evitándose por este medio el fastidio que causaria la repeticion de las notas comunes á muchas substancias, quando hubiese necesidad de compararlas todas. A falta de la nota esencial, que no siem-

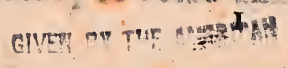


pre se encuentra, nos valemos del carácter facticio, substituto del esencial, y que desempeña ventajosamente sus veces, quando los objetos que se exâminan ó describen, se han sujetado de anteriano á un método ó sistema exấto.

Convencido de la impertancia de esta materia, y de la absoluta necesidad que hay de observarla escrupulosamente en la Historia de los vegetables, para llevar la Botánica al mas alto grado de perfeccion, me he propuesto ocupar la atencion de mi llustre Auditorio con la exposicion del artícilo XF de la Filosofia Botánica del Caballero Cárlos Linneo denominado Adumbrationes, para que enterados de su utilidad los que se dedican al cultivo de este importante tamo de la medicina, venzan los primeros obstáculos que hallan los principiantes en la completa descripcion de una planta, para lo qual es indispensable tener una previa y cabal idea de los términos técnicos del arte explicados en el Curso Botánico del Dr. D. Casimiro Gomez de Ortega, sin cuyos preliminares seria imposible dar un paso con acierto en el asunto.

No dexará de parecer extraño á algunos, que pretenda yo explicar en este discurso las reglas que deben guardarse en el órden de una buena descripcion, quando hace siete años que oimos á nuestro Catedrático un prolixo comento de los cánones de Linneo relativos á este punto, no contentándose solo con hacer una: distinta y clara exposicion de su doctrina, sino empleando en cada curso mas de dos meses en el exercicio práctico de las descripciones, para instruccion $y$ aprovechamiento de todos los discípulos; pero cesará la admiracion de qualquiera que hiciere este reparo, quando considere, que en cada curso se presentan pro-.. 
fesores nuevos en los tres ramos de Medicina, Cirugía y Pharmacia, que desean su adelantamiento en el estudio del reyno vegetal, y ademas, hay tambien hasta el dia varios aficionados, á quienes se les resisten de tal modo las doctrinas de Linneo, por mas que las estudian y practican, y por mas que se empeñan los maestros en hacerlas comprehender, que hacen un papel ridículo entre los verdaderos profesores, y en el público, quando tratan con aquellos algun punto de Botánica, ó gquando eseriben para este algunas noticias útiles sobre la misma materia. A estos pues, y no á los discípulos aprovechados, se dirigen las presentes advertencias con el único fin de imponerlos en el método mas exâcto de describir un vegetal, libertándolos así del sonrojo que sufrirán en la Sociedad, siempre que dirigidos por su capricho, y- privados de los primeros elementos de esta Ciencia, pretendan corregir en tono de máestros á otros profesores de mérito, cuyes trabajos han logrado la aprobacion de los mas inteligentes. ( $\mathrm{r}$ )

Esta es la única prevencion que tengo que hacer á mi distinguido Auditorio sobre el discurso que voy á pronunciar, el qual no siendo mas que un comento de los aforismos de Linneo en el artículo citado, no requiere mas order que el que sigue este célebre Autor en sus mismos cánones.

Dice pues en el primero que las Adumbraciones ó Representaciones comprehenden la historia de

(1) Ya vió cl Público de Miéxico las muchas sandeces y puerilidides ea que incurrió el aficionado J. L. M. en los suplementos á las gazetas de literatura de 5 de Noviembre de 94 , y de 30 de Fnero de 95, manifestando en ambas un torpísimo conocimiento de las docirinas botánicas, no sirviendo de otra cosa sino de excitar la risa de los prolesores instruiúos, así de España, cono de México. 
cada planta, por consiguiente los Nombres, las Etimologras, las Clases, los Caratéres, las Diferencias, las Variedades, los Sinónimos, las Descripciones, las Estampas tos Lugares y los Tiempos: á lo que se pueden añadir sus usos y virtudes.

- Los nombres son tan precisos en todas las ciencias, que sin ellos se perderia el conocimiento de las cosas, como dixo San Isidoro: por esto mismo es indispensable en la Botánica aplicar un nombre de cada especie, porque de hada serviria tener completa la historia de todos los vegetablés si carecieran de denominacion; esta. no debe ser qualquiera que se presente á la imaginacion del hombre, sino que debe estar apoyada con algun fundamento sólido para evitar la confusion en tanta multitud de individuos, y para que se adnita sin' tepugnancia por todos los Sabios y Profesores de la Ciencia.

En la Botánica se distinguen ocho especies de Nombres, que son el Clásico, el de Órden, el Genérico, el Específico, el Trivial, el Variable, el Sinónimo y el Provincial ó propio de cada país. Los dos primeros nos dan á conocer la. Clase y el Órden á que corresponde cada una de las especies: con el Genérico distinguimos los diferentes géneros comprehendidos en una misma clase: el Específico nos da una clara idea de cada especie en particular: el Trivial sirve de substituto al específico para no fatigar la memoria con la enumeracion de las especies: el Variable demuestra las variedades que suelen presentar muchas especies al $S i$. núnimo enseña los diferentes. nombres con que han distinguido los Autores los vegetables de que han tratado; y el Vernáculo ó Provincial indica los diversos nombres con que son conocidas las plantas en cada país. 


\section{(5.) \\ NOMBRE GENERICO.}

14 Nombre genérico debe ser Carafterístico, Botánico ó Recomendable.

El Caraiterístico, que otros llaman Instructivo, es el que se saca de la estructura de la flor ó del fruto, ó bien se toma del hábito de la Inflorescencia, ó de alguna qualidad de la planta, y pueden ser griegos ó latinos, como los siguientes.

GRIEGOS.

Hematoxylion. . . Leño de color de Globularia. ... por las flores puessangre.

Adenantbera..... Antera glandu- Rubia...... por el color rubio

losa.
Ceratocarpus. . . . Fruto con cuer- Asperula..... por la aspereza de

Ceratocarpus... . Fruto con cuer-Asperula.... por la aspereza de Glysirrbiza...... Raiz dulce. Tusilago...... por la virrud de
aplacar la tos. Glysirrbiza..... Raiz dulce. Tusilago..... por la virrud de

\section{LATINOS.}

tas en globo.

El nomb́re Botánica es sucedáneo del Característico, y se saca del apellido de aquellos profesores que han aumentado la Botánica con sus descubrimientos ú observaciones, de aquí los nombres de Linnaea, Tournefortia, Plumieria, \&c..

E1 nombre Recomendable se toma de algunos varónes ilustres que enriquecieron la Botánica erigiendo jardines públicos, ó dotando cátedras para la enseñanza de esta ciencia, ó bien costearon algunas expediciones dentro y fuera de la patria, y publicaron á sus expensas los trabajos de estos viages, como lo han practicado uno y otro nuestros. Augustos Réyes dentro y fuera de España, á beneficio de sus vasallos, á quienes en perpetua memoria de su münificencia y liberalidad se han consagrado los géneros nuevos llamados

Carludovica. por los Autores de la Flora Peruana. Aloysia..... por Don Antonio Palau y Verdera. 
genéricos.

Se deben pues excluir para siempre los nombres

I. Sexquipedales ó de muchas sílabas, como Leuconar. cissolirion, Coriotragematodendros, Hipopbyllocarpodendron.

2. Los Provinciales, como Malabarica, Indica, Germánica y otros.

3. Los Equívocos, como Astragaloides, Anagallidastrum.

4. Los Compuestos de dos diceiones latinas unidas y separadas, y los Hibridos, como Bella donna Coma aurea Chrysantemindum.

5. Los Relativos ó que se refieren á otros géneros como Poiggonifolia, Polyfolia, Linodendron.

6. Los Religiosos, como Pater noster, Spina Christi, Calceus Mariae.

7. Los Comunes á algunas clases, como Truscus, Funguis, Filix, Alga.

8. Los dedicados á algunas Personas por amistad, interes ó adulacion, quando no han contribuido á los progresos de la ciencia como la Aubrieta, Lancisia, Bonarota.

9. Los que son propios de alguños animales, como el Elepbas, Meleagris, Natrix, Eruca.

I0. Los comunes á algunos miñerales, como Molibdena, Granatum.

II. Los tomados de alguina region, como Ternatea, Molucca, Cayra.

12. Los Econúmicos, como Candela, Serra, Corona.

3. Los Aratónicicos, como Umbillicus, Auriculit, Eviglotis.

14. Los Médicos, como Hepatica, Cardiaca, Tulmeraria, Paralisis. 
15. Los que significan una misma cosa, como Canaria, Canarium, Mellicocca, Mellicoccum.

$Y$ otros varios que pueden verse en la Filosofia botánica de Linneo.

\section{NOMBRE ESPECÍFICO.}

$7 \mathrm{~L}$ nombre específico genuino, es el que distingue una planta de todas sus congéneres, y se distingue en esencial y sinóptico. El específico sinóptico impone á las plantas congéneres las notas correspondientes al uno de los dos miembros de su division, y el específico esencial ofrece una nota singular de la diferencia, $\delta$ sea propia solamente de su especie.

Este se recomienda por su certidumbre, claridad y brevelad, y por tanto debe preferirse al sinóptico siempre que pueda componerse como los siguientes.

Pirola scapo anifloro,

Convallaria floribus verticillatis.

Debe tomarse solamente de las partes permanentes y constantes de la planta, como la raiz, el tallo, las bojas, los fulcros, la ingiorescencia y la fructificacion, atendiendo á el número, figura, proporcion y situacion de todas estas partes, y no valerse jamas de las que varian con frequiencia; por consiguiente serán siempre de menor aprecio los que se sacaren con respecto 1. A el tamaño de la planta, como. . Alsine altissima A. major A. minor.

2. Los ideales ó imaginarios como. . Salvia altera $S$. perelegans.

3. Los hipotéticos como. . Marum verum, Acorus aduiterinus.

4. Los relativos como. . Fasobaé Betonicae folio. Melissa Plantaginis folio. 


\section{(8.)}

5. Ios históricos como. . Samolus Talerandi. Conyza. media Matbivli.

6. Los regionales como. . Titbymalus Americanus. Convolvulus Zeglanicus.

7. Los griegos como. L Lotus tetragonolobus. Mimosa platykeratos.

8. Los estacionarios como. . Narcissus serotinus. $T_{u-}$ lipa praecox.

9. Los metafóricos como. . Prunus insana. Urtica mortua.

I. Los negativos como. . Bidens folio non disecto. $L y$ simachia non papposa.

I I. Los comparativos y superlativos como. . Pilosella major, minor birsuta. Alsine altissina.

12. Los económicos como. Agrimonia officinarum. Rubia tinctorum.

I 3. Los semejantes á otras cosas como. . Agaricus tubae falopianae instar.

14. Los tomados del color como. . Brassica viridis. Hyoscyamus niger.

I $5 . . .$. del olor como. . Hypericum bircinum. Melo moschatus.

16. ...... del sabor, como. Apium dulce. $\mathrm{C}_{i-}$ chorium amarum.

I $7 . . .$. . de las virtudes, como.. Rbamnus catharticus. Solanum furiosum.

18....... de la vellosidad, como... Salvia birsuta. Persicaria in aquis glaberima.

$19 . . . .$. de la duracion, como. . Fenotbera biennis. Heliantbus annuus.

$20 . . . \ldots$ de las partes de la planta aumentadas, còmo. . Beta lato caule. 


\section{(9.) \\ NOMBRE TRIVIAL.}

IXE que el nombre trivial servia de substituto al específico para no fatigar la memoria, y para evitar el fastidio que causaria la repeticion de este en la enumeracion de muchas especies.

El Ilustre Linneo fué de parecer que los nombres triviales se tomasen libremente de qualquiera nota que pudiese acomodarse á la planta, y que se compusiesen de una sola diccion, como que carecian de leyes basta entónces; pero su célebre discípulo Juan Murray los sujetó á ciertas reglas en la erudita oracion que publicó sobre esta materia en el Jardin de Upsal el año de 1782 , la qual se halla inserta en la Filosofia botánica impresa en Madrid el año de I 792 , é ilustrada con notas por el célebre y Sabio Botánico el Dr. Don Cásimiro Gomez de Ortega, en donde se prescribe.

I. Que se compongan de una sola voz y no de dos, como los antiguos Chenopodium Bonus Herricus. Teronica Anagallis aquatica.

2. Que se pongan despues del nombre genérico, como Erantbus bijiorus. Ipomoea Macrorrbiza. Gaura Oenotheriflora. Heliantbus alatus. Solidago angulata. Diantbera sexangularis. (I)

3. Que se aplique á las especies que sean únicas en su género, como Castilloa elástica. Cbyrantbodenáron Pentadactylon de la Flora Mexicana.

(1) Géneros y especies nuevals descritas y denominadas por los Señores Botánicos de la Expedicion de Nucva España, y publicados mucho despues por Don Joseph Antonio Cavanilles con los nombres de Milla biflora. Ipomoea stans. Gaura mutabilis. Coreopsis elata. Cineraria praecos. Justicia sexangularis. 


\section{(10.)}

4. Que es mejor el que incluye las notas de la diferencia que hay entre las especies congéneres, como Croton Dioicum. Silene dioica. Cleome gynandra.

5. Que indique aquella parte que compone el caráeter específico, como Entbomantus tuberosus. Pterospermum scandens." Melampodium perfoliatum. Coreopsis bipinnata. Cotyledon tomentosa. (2)

6. Que la yerba subministra un carácter ventajoso particularmente las hojas, como tambien la Inflorescencia y la misma flor: v. g. Alisma cordifolia. Scandix nodiflora. Sida umbellata.

7. Que sean griegos ó latinos, pero no demasiadamente largos, como Salvia Leucantha. Salvia Polystacbia. Valeriana capitata. Mirabilis viscosa. (3)

8. Que el simil de que se deriven sea muy conocido, como quando decimos hablando de las hojas que son acorazonadas, aovadas, lanceoladas, palmeadas, en figura de cuña \&c.

9. Que la idea que encierra no sea contraria á la idea del género, como Chrysantemum Leucantbemum. Sagittaria lancifolia.

Io. Que se admitan alguna vez sin esta circunstancia con tal que se tomen del nombre del Inventor, ó del que contribuyó á la propagacion de sus usos y virtudes, como en la Malva Boerbaviana. Plantago Loew flingi. Begonia Balmiziana.

I I. Que se pueda usar del nombre pharmaceútico

(2) Géneros y especies nuevas de nuestra Flora Mexicana que el citado Señor Cavanilles ha llamado á la primera Cobea scindens: á la segunda Alcina perfoliata: á la tercera Cosmos bipinastus: y á la quarta Cotyledon coccinea.

(3) Especies nuevas de la misma Flora, publicadas con los mismos nombres por dicho Autor. 
como trivial: v. g. Oxalis Acetosella. Papaver Rboeas.

I 2. Que se conserve por trivial el nombre genérico espurio, que se hubiere usado por mucho tiempo, como en el Dracocepbalum Ruyschiana. Salvia Sclarea.

I3. Que se proceda con tiento en la composicion de estos nombres sacándolos de las diferencias específicas impuestas por algunos Botánicos antecesores, como Rheede, Rumphio, Barrelier, Petiver, Plukenecio y otros, cuyos nombres pueden citarse solo como sinoónimos, hasta que se descubran con observaciones posteriores algunas notas omitidas por estos.

i4. Que son de ménos valor los nombres triviales característicos que callan la parte á que se refieren, como en la Amaryllis undulata. Asclepias undulata, que en la primera son los pétalos ondeados, $y$ en la segunda las hojas.

I5. Los que se toman de las partes ocultas, y ménos constantes en la planta, como en el Glycine subterranea. Arachis bypogaea. Lilium bulbiferum. Arum maculatum.

I6. Los que se sacan de notas que no existen en el vegetal, como la Patria: v. g. Erigeron Canadense. Tamarix Germanica.

I7. Los compuestos con atencion al suelo y estacion en que nacen, como Veronica arvensis. Hypericum montanum Ranunculus vernalis.

I 8. Los que indican el tiempo de su florescencia, como Adonis vernalis. Bignonia Equinoctialis.

I 9. Los que proponen el olor, color y sabor de la planta, como Polemonium caeruleum. Iris foetídissima. Polygula amara.

20. Los que abrazan el nombre vulgar de los paises, como Heliconia Bibai. Paullinia Cururu. 


\section{(12.)}

21. Los que se comparan con otros vegetables, y los acabados en oides, astrum, ella y otras terminaciones semejantes que tengan relacion con ellos, como Psoralea Corylifollia. Atropa Pbysalodes. Brassica Erucastrum. Gentiana amatella.

22. Los que indican la duracion de la planta, como Lunaria annua. Aster tenellis.

23. Los que expresan el uso económico que tiene el vegetal, como Dipsacus Fullonum. Galega tinctoria.

24. Los que exponen sus virtudes y usos médicos, como Inula disenterica. Ranunculus abortivus.

25. Los que tienen conveniencia en el sonido ó en la idea, como Convolvulus pentaphylus. Convolvulus quinquefolius. Silene nocturna. Silene notiflora. 26. Ultimamente no se admitirá jamas denominacion que anuncie discordias, incluya sátiras, ó que exponga alguna historia inútil de la planta.

\section{NOMBRES VARIABLES.}

$\mathrm{H}^{\mathrm{L}}$ Nombre variable demuestra las variedades que suelen presentar muchas especies de plantas en el tamaño, plenitud, y rizado de sus hojas, en el olor, color y sabor, en la vellosidad y fulcracion.

Las variedades naturales resultan del sexô de las plantas, todas las demas son monstriosas y provienen del clima, del viento, del Sol, del riego y del diverso beneficio que se da á las plantas en distintos suelos.

El nombre variable se distinguirá fácilmente del Genérico y del Específico, escribiéndolos todos con letras de diferente tamaño como en el exemplo siguiente. 


\section{(I 3.)}

Convallaria scapo nudo, corolla plena.

La primera voz denota el nombre genérico, las das siguientes la diferencia, y las dos últimas la variedad.

En toda descripcion es conveniente exponer las variedades á que está sujeta la planta que se da á conocer quando provienen de las causas asignadas, $\mathrm{y}$ omitir las ligeras variedades, que hubieren producido la casualidad, las enfermedades, los insectos y la distinta edad del vegetable; pero sobre todo se tendrá sumo cuidado en no imponer á una planta natural un nombre que se oponga ó repugne á sus variedades, para lo qual es muy del caso tener presente el siguiente exemplo que propone Linneo en su Crítica botánica, que aclara suficientemente la materia.

La Espuela de Caballero (Delpbinium Ajacis) es una planta que en su estado natural produce el tallo poco ramoso, y las flores azules y sencillas.

Varía muchas veces con flores encarnadas. (sencillas) con flores blancas. . . (sencillas) con flores plenas. . . ( azules) con flores plenas. . (encarnadas) con flores plenas. . . . (blancas)

Fara distinguir pues esta especie de sus congéneres en el estado natural bastará decir DELPHINIUM caule subdiviso sin añadirle Corollis caeruleis simplicibus, porque son siempre de este modo en su estado natural.

Si varía con flores blancas ó encarnadas quedará suficientemente aclarada la especie y la variedad poniendo

Delphinium caule subdiviso Corollis albis.

Desphinium caule subdiviso Corollis rubris. 


\section{(14.)}

sin que sea necesario añadir á una y otra variedad la voz simplicibus porque solo se apartan de la natural en el color. Pero si las flores fuesen plenas y azules, plenas y encarnadas, ó plenas y blancas, se explicarán sus variedades del siguiente modo.

Delphinium caule subdiviso Corollis plenis.

Delphinium caule subdiviso Corallis plenis rubris.

Delphinium caule subdiviso Corolis plenis albis. omitiendo en la primera variedad el color azul, porque este es el mismo que tiene en el estado natural; pero añadiéndolo en la segunda y tercera porque se apartan de la natural no solo en la plenitud, sino tambien en el color.

Por último, se debe tener presente que las variedades producidas por el cultivo se pueden reducir á su estado natural, trasladándolas á un suelo estéril, y privándolas del beneficio que las hacia monstruosas.

\section{DE LOS SINÓNIMOS.}

T OS Sinóninsos son los diversos nombres impuestos por los Fitólogos á una misma planta, y estos ó son Genéricos, ó Específicos, ó Variantes.

Son de suma utilidad estos nombres en la Botánica para discernir sin equivocacion los vegetables, y para saber quanto han escrito de ellos los Botánicos, y por tanto se deben añadir en las Descripciones citando en primer lugar el mejor Sinónimo que se hallare, ya sea de otro Autor, ó del mismo que arregla la Sinonimia, juntando los que fueren semejantes, principiando nueva linea con cada uno de ellos, indicando en todos el Autor, la edicion y la página, señalando con una estrella el nombre del que lo inventó, y poniendo 


\section{(I 5.$)$}

al fin de todos si se quiere, el nombre vulgar del pais en que se cria la especie.

\section{DEL NOMBRE CLÁSICO Y DE ÓRDEN.}

T OS nombres de la Clase y del Orden sirven para

reducir cada género y cada especie á la que pro. piamente les conviene, y se sujetan á las mismas leyes que el nombre genérico; se suprimen quando se anuncia un vegetal, añadiéndolos solamente en las descripciones, y para ser buenos deben incluir una nota esencial, constar de un solo vocablo, y no componerse con relacion á las Virtudes, á la Raiz, al Fuste, ó Yerba, y á la Traza de la planta.

\section{DE LAS ETIMOLOGÍAS.}

T AS Etimologías denotan el orígen y raiz de las palabras, y por tanto es muy conveniente explicar en las descripciones la derivacion del nombre genérico que se da á conocer: así lo han practicado con mucha erudicion y en honor de la Ciencia los célebres Botánicos Don Hipólito Ruiz y Don Joseph Pavon en el tomo primero de su Flora Peruana, Obra digna de los mayores elogios que inmortalizará sus nombres, y acreditará á los Extrangeros lo mucho que ha debido en todos tiempos la Historia Natural á los Españoles. Se infiere de lo dicho que deberán tenerse por absurdos todos aquellos nombres genéricos que no tienen alguna raiz, derivacion ó significacion, como igualmente todos los Regionales cuyas lenguas ignoran los eruditos, los que están sacados violentamente y sin propiedad de los Héroes y Botánicos á quienes se ban con- 
sagrado, ( $\mathrm{I}$ ) debiendo por 10 mismo tener únicamente la preferencia los Griegos y Latinos, y los que se dedican á Botánicos beneméritos \&zc.

\section{DE LA CLASE Y ÓRDEN.}

C LASE es la conformidad de varios géneros en las partes de la fructificacion, con arreglo á los principios de la naturaleza y del Arte, y el Órden es una subdivision de las Clases, á fin de que no haya que distinguir de una vez mas géneros, que los que alcanze con facilidad la imaginacion. Las Clases son Naturales, ó Artificiales como los Sistemas que las abrazan. La Clase natural debe comprehender géneros naturales: esto es que tengan caractéres comunes á todos. los géneros admitidos en ella; lo que solo se consigue con la juịciosa y exâcta comparacion de los individuos. La Clase artificial contiene géneros artificiales, ó que convienen en una sola nota de la fruetificacion. El Órden de las Siliquosas por exemplo, comprehende todas aquellas plantas, que tienen el Cáliz y la Corola de quatro hojillas, seis filamentos quatro mas largos que

(1) Takes el ridículo y extravagante nombre de Castella que cl aficionado J. L. M. impuso á la Castilla elástica de mi Catedrático, pretendiendo corregir sin principios sólidos la denominacion y descripcion del Arbol del Ule que la Expedicion Botánica consagró, como verdadero género nucvo á la memoria del difunto y benemérito profesor D. Juan del Castillo. Veanse los suplementos á la gazeta de literatura de 2 de Julio y 5 de Noviembre de 1794 , con los infinitos absurdos que comctió despues el mismo aficionado en el de 30 de Enero de 95. queriendo satisfacer á los defectos que manifestó Don Vicente Cervantes de su extravagante correccion en el Acto de Botánica, los que se expusieron por menor en el suplemento á la gazeta de México de 30 de Mayo de 95. 


\section{(I 7.)}

los otros dos, y el fruto una Vayna 6 Vaynilla, y pot consiguiente una Clase natural; pero la Clase Pentandria de Linneo abraza gêneros enteramente disímbolos en su fructificacion, conviniendo solo en la nota comun de tener cinco filamentos, por la que justamente se llama Clase artificial.

Consiguientemente el Sistema natural compuesto solo de Clases naturales se llama Sistema, ó Método natural; y Artificial el compuesto de Clases artificiales en el sentida que queda expresado.

A unque el Sistema natural sea el mas útil, y el ûnico á que deben dirigir sus tareas todos los Botánicos para perficionarlo, $y$ concluirlo si es posible, como se halla todavía imperfecto, se hace necesario adoptar un Sistema artificial, que es incontestablemente mas ventajoso que el mismo Método natural para el conocimiento de las especies; y estando la opinion comun de todos los Sabios á favor del Sistema sexûal de Linueo no puedo ménos de exhortar á todos los jóvenes que desean su instruccion en esta utilísima parte de la Medicina, á que se dediquen á entenderlo, sin que dexen por esta de aplicarse á la observacion de todos los individuos para perficionar el Método natural que tanto recomiendan Linneo y los demas Clásicos Autoresa

\section{DE LOS CARACTERES.}

$\mathrm{H}_{\mathrm{L}}^{\mathrm{L}}$ carácter es la Definicion del Género, y es de tres especies Esencial, Facticio y Natural.

El carácter esencial subministra una nota muy propia y ingular del género á que se aplica. Será mejor quanto mas abreviado fuere y merecerá propiamente este nornbre aquel, que dé á conocer con una sola. 


\section{(18.)}

idea ungénero distinguiéndolo de todos los demas que están comprebendidos, baxo del mismo Orden natural; debe ser constante en todas las especies, porque de otra suerte dexaria de ser carácter esencial, tales son las escamas del Ranúnculo en la base de los pétalos, las horquillas en los filamentos de la Salvia, y los dientes en los estambres de la Prunela.

El carácter Facticio distingue el género de otros géneros; pero solo del mismo Orden arificial.

Llamarémos pues caractéres facticios todos aquellos que estriban en una nota pur medio de la qual distinguimos un género de los demas que se hallan en la misma seccion ú órden, y que de ningun modo pue. de darnos á conocer los géneros comprehendidos en orros órdenes ó secciones.

Para mayor claridad y precision de este carácter se distribuye regularmente el Orden artificial en otras divisiones sinópticas, que contienen aquellos géneros que convienen en una nota comun, por cuyo medio distinguimos á primera vista los géneros arreglados en una division, de todos los que comprehenden las demas divisiones.

Por exemplo en la Clase Triandria de Linneo se halla desde luego el Orden artificial llamado Monogynia que reune baxo de sí todas las plantas cuyas flores tienen tres estambres y un pistilo. Este órden se halla arreglado hasta ahora en tres divisiones, que son Flores altas, Flores baxas, y Flores gramineas. En la primera division de Flores aitus se halla con otros el género Ixia cuyo carácter es: Roseta de seis pétalos patente, y tres estigmas sencillos, con cuyas notas se distingue fácilmente de la Valericna, Crocus, Iris, y demas géneros arreglados en aquella 
division. Pudiera muy bien hallarse en la segunda division de Flores baxas otro género que tuviera el mismo carácter, en cuyo caso no se diștinguiria del género Ixia sino por ser una flor baxa que no se halla alguna en la division primera; peró si se diera la casualitad de encontrarse un género nuevo con la flor áta, y con el carácter expresado de la Ixia, seria preciso añadir á uno y otro género alguna nota por medio de la quat pudieran distinguirse sin equivocacion, lo que formaria un carácter facticio, que otros llaman sobresuliente.

Fi carácter natural reune todas las notas genéricas posibles, y por tanto comprehende en sí al esencial $y$ al facticio.

Este carácter es el que deben arregiar con mayor cuidado los Botánicos, porque él solo conduce á lá exâcta determinacion y conocimiento de las especies. Hemos visto que el carácter esencial disingue ventajosamente los géneros por una nota singular que sobresale cn ellos; pero no se halla estersino en ur pequeño número de los que estan conocidos, y por otra parte puede faltar en alguna especie nueva, en cuyo caso no podrá decirse esencial; el carácter facticio no distingue los géneros sino en un Orden artificial, como queda dicho; luego es indispensable el preferir el caráêter natural para determinar y distinguir con precision los géneros y las especies.

El carácter natural se dispone describiendo cuidadosamente la fructificacion de la primera especie que se halla: se comparan despues las demas especies congéneres que se van descubriendo, $y$ se excluyen todas las notas que discrepan para dexarlo enteramente arreglado. 


\section{(20.)}

Un caráeter natural dispuesto en la forma dicha, sirve á quantos sistemas sean posibles, forma la base de todos, y persevera inmutable aun quando se descubran otros infinitos géneros.

Aunque todo lo dicho hasta aquí se refiere al caráeter genérico, debe entenderse lo mismo del carácter clásico, no obstante de que no se tome en este con tanto rigor.

A los tres caractéres dichos se puede añadir el carácter babitual que consiste en la forma particular, ó traza que presentan los vegetales afines y congéneres conformándose unos con otros en la Placentacion, Radicacion, Ramificacion, Intor sion, Gemacion, Foliacion, Estipulacion, Pubescencia, Glandulacion, Lac. tescencia, Inflorescencia, y en otras varias cosas.

Este carácter habitual sirve de mucho al Botánico consumado que sabe aprovecharse de las ventajas que presta en muchas ocasiones, para el mejor discernimiento de los géneros; pero es muy perjudicial á los principiantes que faltos de experiencia quieren acomodarlo desde luego, segun les dicta su poca observacion, é incurren en los mismos errores en que cayeron varios célebres Botánicos de los antiguos, quando por falta de sistema de fructificacion; hicieron uso de él en la colocacion de las especies que arreglaron.

Resulta de lo dicho que la Disposicion primaria de los vegetales se debe tomar de sola la fructificacion, y que toda nota caraiterística debe deducirse del numero, figura, proporcion y situacion de todas las partes de la fructificacion que sean diferentes. 


\section{(2 I.) \\ DE LA DESCRIPCION.}

- A Descripcion es el caráiter natural de tcda la planta, $y$ ba de describir todas sus partes exteriores.

Fste fundamento prescribe el métndo con que se deben hacer las descripciones de las plantas, en las quales no solo debemos atender á la forma de las raices, de los tallos, de las hojas y de la fructificacion, sino observar tambien escrupulosamente los pezones de las bojas, los cabillos de las fores, las or ejuelas, las bráiteas, las espinas y aguijones, las glándulas, la pubescencia, las yemas y su foliacion, la inforescencia, $y$ por último todo el hábito de la planta, considerando en todas estas partes el número, figura, proporcion y situacion de cada una, expresándolas sin elevacion ni adornos, sin digresiones ni jocosidades ó equívocos, sino valiéndose únicamente de términos sencillos, claros $\mathrm{y}$ adequados, quando no fueren suficientes para practicarlo, los técricos ó del arte.

La descripcion que abraza todas las circunstancias expuestas se llama caráiter natural de la especie, en el qual aunque se guarden las reglas establecidas para el caráeter genérico natural, se incluyen en él muchas notas accidentales, que seria superfluo añadir al genérico, como el olor, color y sabor, el tamaño, la $d u$ racion \&c.

Ademas de lo dicho se debe guardar en una buena descripcion cierto órden, en el qual se han de disponer las materias, de modo que no desdigan ni se opongan á la sucesion natural con que se desplegan las partes del vegetable, y así será bueno que quando se principia la descripcion por la raiz, se continúen las no. 
tas del tallo, de las ramas, de las hojas y pezones, poniendo despues las orejuelas, las braiteas, las espinas, los pelos \&c. y concluir con la fructificacion. Esta regla se suele invertir muchas veces, poniendo en primer lugar el carácter genérico natural sacado de la frustificacion, y expresando despues de él las notas correspondientes á el carácter natural específico, tomado de todas las partes de la planta.

Para mayor claridad de la descripcion se colocan las diversas partes del vegetal en párrafos separados en distintas líneas, ó distinguicndo á estos por medio de dos rayitas, ó últimamente en una série continuada de renglones, principiando con letras diferentes cada parte del vegetable, segun lo ha practicado el cém. lebre Jacquin Catedrático de Viena en su erudiúsima Obra de Plantas Americanas.

Se debe evitar en toda descripcion la suma prolixidad que han usado algunos Autores para expresan sus pensamientos en las cosas que no demandan una atencion particular, como el color verde en las hojas, la rigurosa exâctitud en las medidas y otras semejantes. pero no se debe incurrir en el extremo contrario, haciendo las descripciones tan concisas, que se omitan al. gunas notas esenciales á la planta, quales son las Est pulas, Brábteas, Glánóulas, y otras varias que puedan subministrar algun carácter distintivo de la especie.

Por lo que respecta á las medidas no hay necesidad alguna de observar el rigor geométrico que introduxo Tournefort, á quien siguieron otros; porque no hay cosa mas variable en las plantas que el támatio, y porque la esencia de una buena descripcion no depende en ninguna manera de la exâctitud en las medidas, bastará pues valerse de la proporcional que nos 
encarga Linneo, comparando las diferentes partes de la planta unas con otras, $y$ quando se quiera expresar en particular el tamaño de qualquiera de estas partes, usarémos del cabello, línea, uña, pulgada, palmo memor ó xeme, del palmo mayor, pie, codo, brazo y estatura bunzana, usadas por el mismo Linneo y admitidas por tudos los Botánicos, reduciéndolas á la vara castellana, segun se prescribe en el Curso de Botánica del Doctor Don Casimiro Gomez de Ortega.

Finalmente para que una descripcion sea completa debe estar acompañada de buenas estampas, si es posible, debe expresar los principales lugares, climas, suelos y tierras en que se cria la planta, segun el tiempo de su vegetacion, de su germinacion \&c. y por último indicará los diversos usos económicos y las principales virtudes medicinales.

\section{DE LAS ESTAMPAS.}

T AS estampas ó diseños son unos signos represenHa taivos de los objetos que queremos dar á conocer, y que á primera vista nos manifiestan el conjunto de las principales notas, que existen en la cosa figura$\mathrm{da}$, por lo que se llaman con toda propiedad descripciones en compendio.

Aunque las estampas no pueden expresar con exâetitud muchas circunstancias dignas de aprecio en los vegetables, no se puede negar su utilidad quando estan acompañadas de buenas descripciones, porque en el instante nos presentan las notas esenciales de la planta, aunque nos oculten el olor, sabor, durcza, aspereza, lisura y otras qualidades que no pucden representar el buril ni el pincel. 


\section{(24.)}

No puede negarse que las estampas aumentan considerablemente el costo de las obras que se publican con este adorno, particularmenre las de Historia natural, en donde es necesario representar tanta multitud de objetos, haciéndose por lo mismo inasequibles á muchos Profesores de mérito que carecen de facultades para adquirirlas; esto pudiera remediarse haciéndose dos ediciones de todas las obras útiles, en una de las quales podian emplear su magnificencia los Soberanos, y otros Protectores de las Artes y Ciencias, y en la segunda se suprimiria todo el luxo, que á competencia se están disputando las Naciones europeas para excederse unas á otras, privando de su uso á la mayor parte de los Profesores que son los que mas. las necesitan

Estas últimas ediciones prestarian á los Botánicos y Naturalistas todas las uilidades que les proporcionan las obras de mas costo, con tal que sus estampas solo tuvieran bien diseñados los contornos de las raices, de los tallos, de las hojas, de las flores \&c. y señaladas las principales. líneas interiores de las mismas partes sin sombra alguna, como lo están las estampas de Fuchsio, de Plumier y de algunos otros.

De qualquier moda que se hubieren de disponer estas figuras se procurará siempre el que expresen la situacion natural que tienen las plantas en la tierra poniéndolas derechas, inclinadas, énredadas, rastreras, parasíticas sobre árboles, ú otros cuerpos, y en la misma agua si fuere necesario. Se pondrán en su tamaño natural las que no excedieren la marca del papel que se hubiere elegido, y quando fueren mayores se dibujará solamente un ramo, añadiendo en la descripcion la altura, grueso y tamaño de las hojas, flores y frutos ss no cupieren en el papel, cuya diligencia se prac- 


\section{(25.)}

ticará con todos los árboles, arbustos y matas, poniendo á parte si se quiere, todo el árbol ó planta grande en compendio, y aumentando por medio del Microscopio las partes muy menudas que no se perciben en su estado natural.

Por último se podrán llamar solamente buenas las estampas que teniendo todas las circunstancias dichas, expresen con puntualidad las partes mas pequeñas del vegetable, sin omitir las mas imperceptibles de la fruclificacion.

\section{DE LOS LUGARES.}

T OS lugares nativos de las plantas se refieren al Pais, Clima, Suelo y Tierra.

Es de suma importancia añadir en la adumbracion de cada planta el lugar mas acomodado para su vegetacion: esto forma la base principal de la Jardinería, y sin su conocimiento no podria conservarse en los Jardines botánicos tanto número de plantas exôticas, ni seria tan fácil la adquisicion de otras muchas, si se jgnorase el suelo en que se deben buscar, tanto para trasplantarlas á los mismos Jardines, y para la formacion de los herbarios, como para emplearlas en la Medicina y en la Economia.

Por infinitas observaciones de los Botánicos Viageros estamos advertidos de que la longitud y latitud de los lugares son insuficientes para indicar el suelo propio de las plantas, y así será superfluo añadirlas en las descripciones; pero podrian expresarse las alturas porque consta de los mismos, que en temperamentos iguales prosperan por lo comur casi unos mismos individuos, y á todos nos consta que las plantas de 
tierras calientes son absolutamente diversas de las que nacen en los temperamentos frios.

Los lugares nativos de las plantas son ó comunes, 'o particulares. Por lugares comunes entendemos las quatro partes del mundo, Europa, Asia, Africa y América, y distinguimos en ellas las islas, reynos, provincias, ducados, condados $\mathfrak{G} c$.

Los particulares son el mar, los lagos, los rios y arroyos, las fuentes, las lagunas y las orillas de todos estos, los pantanos y los tanques, los lodazales, Ios terrenos inundados y sumideros, los alpes, montes, collados y valles, los lugares per̃ascosos, pedregosos $\mathrm{y}$ areniscos, los bosques y las selvas, tanto naturales como artificiales, los prados y potreros, los campos eriales y de sembrar, los jardines y buertas, los ribazos, los terrenos incultos, los estercoleros, \&c.

En todos estos sitios se crian generalmente distintos vegetales; y por tanto convendrá especificarios: en la descripcion, añadiendo para mayor inteligencia la calidad de la tierra en que nacen, explicando si es arcillosa, arenosa, calcárea, margosa, de mantillo, ó compuesta de algunas ó de todas estas especies.

\section{DE LOS TIEMPOS.}

$\mathrm{H}^{\mathrm{L}}$ tiempo de vegetar con vigor las plantas, de H germinar, de desplegar las primeras bojas, de producir las primeras flores, de velar, de sazonar el: fruto, $\mathrm{y}$ el de despojarse de la boja, indican el clima. Servirian de muchísimo provecho á la Agricultura las observaciones exâctas que se emprendiesen en cada pais sobre todos estos puntos, para adelantar o retardar las siembras de muchos vegetales, para cal- 


\section{(2\%)}

cular anticipadamente y con mayor acierto que hasta ahora la abundancia ó escasez de las cosechas, y para otros muchos fines tan útiles como ventajosos á la sociedad. Por este motivo no será fuera de propósito explicar cada parte de este Aforismo, á fin de que se comprehenda lo que debe entenderse por cada una de ellas.

Vegetar con vigor las plantas se dice del tiempo que viven prendidas á la tierra, produciendo sin interrupcion hojas, fiores y frutos, cuya edad se averigua en los árboles por el número de circulos concéntricos que se advierten en el tronco cortado trasversalmente.

La Germinacion es el estado en que se hallan las semillas quando principian á desplegarse las hojas seminales con todas las demas partes adherentes, adelantándose mas ó ménos segun la naturaleza de cada una, y segun son mayores ó menores la humedad y el calor que las favorecen. Hay muchas semillas que requieren ser sembradas luego que ha llegado el fruto á sazonarse como el Café, la Nuez móscada, la Quina, $\& z$. y hay otras que conservan por muchos años su facultad germinativa como sucede en la mayor parte de las leguminosas. Todas por lo general duran mucho tiempo sin alteracion, quando se hallan enterradas á grandes profundidades en lugares secos y templados, de que resulta en muchas ocásiones verse un terreno cubierto de plantas que nunca ha tenido, despues de haberse hecho en él excavaciones profundas.

Son pues, circunstancias indispensables para la Germinacion de los vegetales el calor, la humedad, el ayre y la calidad del terreno, y á pesar de todas estas condiciones se advierte una inmensa variedad en la 


\section{(28.)}

Germinacion de las semillas, haciéndose algunas en un dia como la del Trigo, otras en tres como las del $\mathrm{Na}$ bo, del Rábano, de la Mostaza y de la mayor parte de los cruciformes: la del Eneldo en quatro, de la Lechuga en cinco, la del Pepino en seis, la de Cebada en siete, la del Apio y del Peregil en quarenta, la del Almendro en un año, la del Rosal en dos \&cc. notándose bastante diferencia en estas mismas especies, segun la calidad del clima, del suelo \&c.

La Frondescencia es el tiempo en que cada planta desplega sus primeras hojas: lo qual está igualmente sujeto á muchas variedades que dependen de la diversa posicion del terreno, de la naturaleza y edad del vegetable, del calor del Sol, y de otras circunstancias que retardan ó aceleran la expansion de estas partes. En las familias de los Musgos y Pinos se cubren de hojas muchas especies durante el Invierno. Las plantas gramineas y azucenadas lo executan en la Primavera. Los árboles de la India y de las Américas se hallan en su mayor vigor en tiempo de Estío en las regiones Europeas, y otros vegetales como los. Hongos, Helechos y algunos Musgos vegetan en Otoño, cuya diferencia indica que á ciertas especies de vegetales convienen determinados grados de calor para desplegarse; pero en las tierras calientes de Nueva España se observa una vegetacion continua brotando en todas estaciones nuevos tallos, hojas y flores, aunque sea el mayor empuje de la Sábia en ciertos tiempos, para producir en mayor abundancia dichas partes.

La Florescencia es el tiempo en que manifiestan las plantas sus primeras flores, lo qual puede considerarse baxo dos aspectos, el primero con atencion á la estacion del año en que lo executan, lo que se lla- 


\section{(29.)}

ma simplemente Florescencia ó Florescencia annua, y el segundo con respecto á la hora en que se abren, lo que se puede decir Florescencia diaria.

Hay muchos vegetales que florecen constantemente en determinadas estaciones del año, sean frios ó calientes los climas que los producen, los quales transportados á otros climas en que el temple de la atmósfera $y$ las estaciones son diferentes, mudan el tiempo de la Florescencia, no manifestando sus flores sino en aquellos meses en que la temperatura es análoga á la que los hizo florecer en su suelo nativo.

Pero generalmente hablando, las plantas de las tierras mas frias y las de los alpes florecen en la estacion en que los Europeos señalan su Primavera.

Las que crecen en los trópicos y en los climas templados, manifiestan sus flores durante el Estio de los mismos Europeos.

Las plantas de los climas templados situados baxo el paralelo de Europa, pero mucho mas occidentales como el Canadá, la Virginia, el Misipipí, no florecen hasta el Otoño, particularmente las vivaces y las annuas que se siembran, ó que nacen espontaneamente.

Las de los paises templados del emisferio äustral, como el Cako de Buena Esperanza, producen sus flores en el Invierno de los Europeos, que corresponde á su Estio, y en los paises templados de la Zona tórrida como en México, se observa una vegetacion casi igual á la que se advierte en las provincias meridionales de España, prescindiendo de algunas ligeras diferencias que ocasionan ciertas circunstancias accidentales.

La Florescencia diaria, que otros llaman Vigilias de las Plantas, comprehende no solamente las ho. 


\section{(30.)}

ras del dia en que se abren las flores, sino tambien aquellas en que se cierran, lo que está sujero como en la Florescencia annua á muchas variedades. Las florcs que tienen esta propiedad se llaman Flores solares, y se distinguen por razon del modo con que lo executan en Meteóricas, Trópicas y Equinocciales.

Las Flores Meteóricas son aquellas que no guardan una regla fixa en su manifestacion, haciéndolo mas ó ménos tarde por razon de la sombra, por el ayre mas ó ménos húmedo ó seco, ó por la mayor ó menor presion de la atmósfera.

Las Trópicas son las que todos los dias se abren por la mañana y se cierran por la tarde, anticipando ó atrasando la hora de su expansion segun crecen ó menguan los dias, observando en esto las horas babilónicas ó desiguales.

Equinocitales se llaman las que se abren á ciertas y positivas horas del dia, y se cierran tambien en horas determinadas siguiendo el órden de las horas Europeas, ó iguales.

De esta propiedad que tienen ciertas flores de abrirse y cerrarse en determinados tiempos le ocurrió á Linneo la ingeniosa idea de formar un Relow Botánico ó de Flora, con el qual se pueden distinguir en un jardin todas las horas del dia por medio de un número de plantas dispuestas en órden para este efecto, el qual puede arreglarse con los mismos ó diferentes vegetales, en quienes se haya observado de antemano el tiempo de su expansion, bien que señalarán distintas horas que en Upsal, segun fueren las condiciones del clima en que se dispusiere.

Las Vigilias de las Plantas no deben equivocarse de modo alguno con la que Linnco llamó Sueño 


\section{(31.)}

de las Plantas, que consiste en la distinta forma o hábito que toman los vegetales de parte de noche plegando sus hojas de diferentes modos, lo qual es muy distinto de la facultad que poseen las flores de abrirse $y$ cerrarse á ciertas ó á indeterminadas horas, como queda dicho.

Ia Fruftescencia ó maduracion comprehende el tiempo en que las plantas esparcen sus semillas ya sazonadas, y la Defoliacion aquel en que los árboles dexan caer sus hojas, cuyos estados admiten iguales diferencias que la Florescencia y la Foliacion. ( $\mathrm{I}$. )

Para mayor inteligencia de lo que queda expuesto en los artículos anteriores, se añadirá la descripcion del famoso árbol de las manitas de Toluca, al que los antiguos Mexicanos y el Dr. Hernandez llamaron Macpalxóbiguaubitl, y los Botánicos de la Kx. pedicion de Nueva Eepaña Chiranthodendron, acomodándole esta denominacion griega ø̧ue significa lo mismo que la mexicana, y que indica como se dirá despues, el carácter esencial de su fructificacion.

\section{ADUMIBRACION.}

1 L Cbirantbodendron es una especie de árbol que produce

La Raiz leñosa, muy gruesa, horizontal, ra-

(1) Los que quieran tener unas noticias mas individuales de todo lo contenido en este Discurso, deberán consultar la Física de los Arboles de Mr. Duhamel: el primer Tomo de las Familias de Plantas de Mr. Adanson: y las Diseriaciones insertas en la sublime Obra de Linneo intitulada Amonitates Acadenicas, con los títulos de Gemmie arborum, Stationes Plantarum, Metamorpbosis Piantarumn., Calendarium Florde, Prolepsis Plantarum, Coloniae Plantarinn. 


\section{(32.)}

mificada en todos sentidos y poblada en muchas partes de fibrillas delgadas, cubierta de una epidermis de color obscuro, y que se separa fácilmente de la corteza exterior, que por de fuera es de color amarillento y por lo interior blanca como la substancia leñosa, la qual expuesta al ayre adquiere en poco tiempo el color amarillento que tiene la corteza en su exterior.

E1 Tronco es de cinco ó seis varas de grueso, y de casi igual longitud hasta las primeras divisiones de sus Ramos, tiene la corteza un poco áspera y quebrada en muchas partes, como sucede al mayor número de árboles antiguos, y su altura total llega á quince ó veinte varas.

Las $R$ amas se hallan regularmente alternas $\mathrm{y}$ extendidas, las mas viejas tortuosas y las tiernas rollizas, rayadas con líneas que se interrumpen de varios modos, y cubiertas de un tomento sutil de color pardo ceniciento, el qual en las extremidades se hace mas perceptible tanto por su mayor densidad, como por el color amarillo de ocre que adquiere.

Las Hojas inferiores estan alternas, escotadas en la base, y con cinco, siete ó mas gajos, que por sus bordes tienen algunos dientes muy pequeños, obtusos y apartados, lisas y de un verde claro en la página superior, blanquecinas y tomentosas en la inferior, con venas bastante salientes y de color de ocre que les presta el tomento que las cubre, el qual visto con un lente se observa en forma de estrellas ó de hacecillos diseminados en toda la superficie inferior de la hoja, entre otro número mayor de estrellitas compuestas de tomento blanquecino: su mayor longitud es de catorce á quince pulgadas, y su mayor anchura de seis á siete: Lás hojas últimas de los ramos son tomentosas 


\section{(33.)}

por una y otra parte, y de color de ocre algo mas claro.

Los Pezones son rollizos, incrasados en la base, casi tan largos como las hojas, y cubiertos con el mismo tomento que éstas.

Las Estípulas son aleznadas, algo carnosas, rebueltas, tomentosas, de una media pulgada de largo, y que se caen fácilmente.

Las Flores se hallan opuestas á las hojas formando un racimo ladeado, sencillo y terminal con seis ú ocho flores cada uno.

Los Cabillos son mucho mas cortos que la flor, comprimidos y tomentosos.

Las Bráfteas aovadas, agudas, enteras, carnosas, cubiertas con el mismo tomento que las partes contiguas, puestas de tres en tres en el remate de los cabillos, con una de ellas un poco mas inferior, las quales á primera vista representan un caliz perianthio.

El Caliz no lo hay, si no quiere tenerse por tal las brácteas que quedan descritas.

La Corola de una pieza en forma de campana y persistente ( $I$ ) partida en cinco lacinias oblongas, acuminadas, aquilladas, carnosas, tomentosas, y de color roxo obscuro por de fuera, lisas y de un roxo subido en lo interior, su tamaño es igual al de una azucena mediana. El Nectario lo forman cinco excavaciones cónicas comprimidas por los lados, puestas en el fondo de la corola que rodean al Gérmen, cuya convexîdad so-

(I) Por esta propiedad de permanecer la corola adherida al fruto hasta su maduracion, se puede reputar por caliz perianthio, en cuyo caso puede decirse que tiene caliz doble temando las brácteas por ćl exterior. 
bresale por la parte exterior formando una base de cin. co ángulos.

Los Estambres son cinco flamentas, aleznados reunidos en la parte inferior en un cilindro de color roxo que envuelve al pistilo, sueltos por arriba, encorvados, un poco desiguales, y que representan la mano de una Ave. Las Anteras oblongas, acuminadas, ondeadas, con un surco longitudinal que las divide en dos partes, pegadas al dorso de los filamentos, y mas cortas que ellas, aunque las dos exteriores se excurren por la base hasta cerca del orígen de los dedos.

- El Pistilo tiene un Gérmen alto, aovado con cinco ángulos obtusos: El Estilo de quatro ó cinco ángulos, velloso, un poco mas grueso y algo encorvado. en la parte superior: E1 Estigma sencillo y agudo.

El Pericarpio es una cápsula leñosa, larga, de tres á quatro pulgadas, y de una á una y media de grueso entre oblonga y elíptica, acuminada, de cinco ángulos, cubierta con un tomento de color de ocre, de cinco loculamentos y otras tantas ventallas.

Las Semillas cincuenta ó sesenta en cada fruto, y diez 6 doce en cada celdilla, perfectamente aovadas, lisas, lustrosas y negras, con una glándula globosa de color de naranja, y del tamaño de un grano de mostaza cerca de su base que cubre la cicatriz, prendidas por un filamento muy corto y por el extremo mas estrecho á la parte interior de las. ventallas, y envueltas. entre un pelo casi cerdoso.

El Receptáculo de la misma figura que la cấpsula pegado fuertemente á eila por la parte interior, de modo que forma á primera vista un solo cuerpo, el qual se separa en cinco partes pegada cada una á las ventallas de la cápsula. 


\section{(35.)}

La Descripcion que acaba de exponerse manifiesta el carácter natural del Chiranthodendron, dei qual se extrae fácilmente el carácter genérico, que puede arreglarse del siguiente modo.

\section{CARÁCTER GENÉRICO.}

brácteas.

CALIZ ninguno, si no se toman por él las

COROLA de una pieza campanuda y persistente, partida en cinco lacinias oblongas, acuminadas, aquilladas carnosas: Nectario cinco excavaciones en el fondo de la ccrola que rodean el Gérmen.

ESTAMBRES cinco filamentos aleznados, encorvados, un poco desiguales y reunidos en cilindro por su parte inferior: Anteras oblongas, ondeadas, puestas en el dorso de los filamentos y mas cortas que ellos.

PISTILO Gérmen alto, aovado, de cinco lados; Estilo anguloso, un poco mas grueso y algo encorvado en sú ápice, y mas corto que los filamentós: Estigma sencillo y agudo.

PERICARPIO cápsula leñosa oblongo-elíptica de cinco lados, cinco ventallas y otras tantas celdillas.

SEMILLAAS diez ó doce en cada loculamento, aovadas; lisas, lustrosas, con una glándula globosa cerca de su base, y, envueltas con pelo casi cerdoso.

RECEPT ACULO de la misma figura que la cápsula.

Obs tiene mucha afinidad con el género Bombax de Linneo, aunque se distingue de él en otros muchos caractéres. 


\section{(36.) \\ CARACTER ESENCIAL.}

${ }_{4}^{\mathrm{L}}$ carácter esencial consiste, como queda dicho, 1. en una nota singular y propia del género á que se aplica, por lo que en el Cbirantbodendron deberá sacarse este de la figura y direccion de los filamentos, que como se ha explicado en la descripcion, representan el pie de un páxaro, ó la mano de un mono como quieren algunos.

CARACTER FACTICIO.

He dicho que el carátter faticio ó sobresaliente es aquel que distingue á un género de todos los demas que se ballan colocados en un mismo órden artificial: de donde se colige que así este carácter como el esencial no son necesarios en una Monográfia, en donde no hay' que distinguir el género nuevo que se describe, de los demas que se hallen ya arreglados en algun sistema, debiendo sacarlo del caráiter genérico el Botánico que lo coloca en la clase y órden que corresponde al método que sigue. Sin embargo para que sirva de exemplo á los principiantes, y á fin de que no incurran en los muchos y crasos errores que cometió el aficionado J. L, M. en la correccion que pretendió hacer de la descripcion de la Castilloa elástica, publicada por nuestro Catedrático Don Vicente Cervantes, se puede disponer el carácter sobresaliente del Chirantbodendron en la forma siguiente.

Caliz ninguno, (ó tres Brácteas caedizas) Corola campanuda y persistente. Estambres, cinco filamentos reunidos por la base y separados hácia su medio en forma de un pie de páxaro. Cápsula leñosa de cinco ángulos y de cinco celdillas. 


\section{(37.) \\ NOMBRES Y GENERO.}

E la descripcion y carácter genérico expresado arriba, se infiere que el Arbol de manitas no puc• de reducirse á alguno de los géneros conocidos, y por consiguiente es un género nuevo bien establecido por los Señores Botánicos de la Expedicion de Nueva España, quienes valiéndose de la doctrina que estableció en sus cánones el Sabio Naturalista del Norte, le impusieron el nombre de Chiranthodendron, término compuesto de las tres voces griegas Xeir-Antbos-Dendron, equivalentes á las tres mexicanas Macpalit-XochitlQuaubitl, que en anibos idiomas significan por el mismo órden Mano-Flor-Arbol, de donde se originan las denominaciones de

CHIRANTHODENDRON, que forma el nombre genérico.

macpalxochiquauhite, que es el Sinónimo del Dr. Hernandez, y

ARBOL DE MANITAS, ô con flores en figura de mano, que es el vulgar con que se conoce por los Mexicanos en el dia.

Pudiera muy bien abreviarse la denominacion genérica, dexándola solo con quatro sílabas pała que fuese mas pronta y fácil su pronunciacion, diciendo v. gr. Chirodendron que suena en castellano Arbol de manos; pero estando admitidos los nombres genéricos de cinco sílabas por todos los Botánicos, y expresando por otro lado la voz Cbiranthodendron la parte del vegetable en que se halla el carácter esencial, que son las flores, juzgo que debe preferirse por todos títulos á la. primera aunque mas corta, por carecer de esta circunistancia. 
E1 nombre específico legítima debe distinguir la planta de todas las congéneres como establece Linneo, y así no conociéndose mas especie del Chirantbodendron que la que se ha descrito, será excusado el sacar una diferencia que no puede tener lugar, sino quando. se descubriere la segunda, porque es imposible el conocer hasta entónces en que se distingue una de otra; ( $I$ ) pero sí se le puede imponer un nombre trivial, como lo tienen todos los géneros nuevos en el sistema de vege-

(1) Por no haber observado esta regla el erudito Botánico Don Joseph Antonio Cavanilles en varios géneros nuevos que ha publicado anticipadainente en su Obra intitulada Icones of descriptiones Plantarum, compuesta en la mayor parte de los muchos que han descubierto, descrito, denominado y remitido á Madrid nuestros Botánicos, se hallan varias diferencias muy impropias, como he tenido ocasion de advertir, así en los M S de la Flora Mexicana que se ha servido franquearme el Director de la Expedicion Don Martin de Sesé, como en el Hortus Mexicanus que está arreglando mi Catedrático Don Vicente Cervantes.

En una y otra parte he visto que el Entomanthus glaber que el Señor Cavanilles denominó Lopezia racemosa tiene la diferencia siguiente.

ENTOMANTHUS pedunculis pendulis, capsulis obovatis, ra-. dice fibrosa: con la qual no puede equivocarse jamas la del Entomantbus birsutus descubierto posteriormente y es

ENTOMANTUS pedunculis erectis, capsulis subrotundo-tetragonis, 'radice tuberosa.

Qualquiera de las notas expresadas era suficiente para distinguir una especie de otra, lo que es imposible que suceda con la siguiente diferencia del Señor Cavanilles.

LOPEZIA caule berbaceo, ramoso, foliis alternis, ovato-lanceolatis, serratis, floribus racemosis.

En ambas especies se halla el tallo ramosp y herbaceo, una y otra tienen las hojas alterias, entre aovadas y lanccoladas, y serradas, y el racimo es comun á las dós especies: por lo qué padeceria un gravísimo yerro el Botánico que encontrando con la segunda, la determinase por la Lopezia racemosia del Señor Cavanilles, que como se ha visto es muy distinta; luego no deben impos nerse diferencias á las especies únicas en su género. 


\section{(no}

tales da Limneo, y segun prescribe Murray en su erudita Disertacion sobre esta materia, y así siguiendo la doetrina de sus Cánones en que ordena que las nombres triviales sean griegos ó latinos, podemos aplicarle el trivial Pentadadtylon que significa cinco dedos, con lo que quedará denominada perfectamente esta especic, llamándola Cbirantbodenáron Pentadactylon, ó árbol con jores en figura de mano de cinco dedos.

\section{HISTQRIA.}

7 OS Autores que han tratado de esta planta son el A célebre Dr. Don Francisco Hernandez, el R. P. Fr. Agustin de Vetancurt y el llustre P. Don Francisco Xavier Clavigero: el primero en su Historia de Plantas de Nueva España al folio 5. I. del segundo tomo de la Edicion de Madrid, y en el compendio que de la misma Obra publicó en Roma Nardo. Antonio Recho al folio 283 . en donde se ve una figura muy. impropia, tanto de las flores como de las hojas de este precioso vegetable. La descripcion es tambien muy imperfecta en ambas ediciones, pues solo dicen que es un árbol grande con las flores en figura de mano, y las hojas parecidas á las de la Higuera, aunque mas pequeñas. La edicion Romana las describe semejantes á las del Moral, con las quales no tienen relacion alguna, y suprime enteramente la noticia del fruto que en la edicion de Madrid se expresa ser duro y leñoso. En esta última Cbra tiene el nombre de Macpalxacbitl, cuya denominacion está aplicada impropiamente á una planta herbacea descrita á la página 532 . que por las notas de sus hojas y del sitio en que crece, es sin duda la Malva vitifolia hallada y descrita por los Botáni- 


\section{(4) )}

cos de Nueva España, y publicada mucho despüês con el mismo nombre por el Botánico Don Joseph Antonio Cavanilles; pero en la Obra de Recho tiene la denominacion completa de Macpalxocbiquaubitl, quien aplica únicamente la voz de Macpalxocbitl á la yerba que se acaba de decir.

E1 R. P. Vetancurt en su Teatro Mexicano página 54 dice hablando del Macpalxochitl que "da por "el mes de Septiembre y Octubre una flor roxa de la "forma de una mano de criatura tan bien formada, $y$ "con tal primor tiene las junturas, artejos y dedos, y * palma de la mano, que ni el mejor Escultor la sacara " con mas primor: quando verde está cerrada en forma "de higa, y al irse poniendo roxa se va abriendo y "queda media abierta: nace en tierras frias como en "Toluca, y en los cerros altos de Ayotzingo: es me"diano, y tiene la hoja como la del Encino."

El P. Clavigero trata muy de paso del Macpalxocbitl, á quien aplica tambien el nombre vulyar de Arbol de manitas, de cuya flor, dice, que es semejante al Tulipán, y que su pistilo representa la figura de un pie de páxaro, ó mas bien el de una mona con seis dedos, terminados en otras tantas uñas; en cuya explicacion se echa de ver que se equivocan los filamentos con el pistilo, que es uno solo, y cinco aquellos, como queda explicado.

El célebre Jacquin Catedrático de Botánica en Viena, creyó haber hallado nuestro Cbirantbodendron en el Helifferes Carthageniensis que describe á la página $237=23^{8}$ de su excelente Obra de Plantas escogidas de América, refiriéndolo dudosamente al Macpalxocbiquaubitl de Hernandez; pero se echa de ver que su descripcion no conviene de modo alguno con la 


\section{(4r.)}

que se acaba de dar de este vegetable, ni se puede remotamente sospechar que los hubiera confundido este diestrísimo Botánico si hubiese visto las dos plantas, ó si la descripcion de Hernandez no estuviese tan incompleta, para hacerle creer que podia juntarse con el He. licteres.

\section{CLASES.}

TOS Caractéres expresados en la descripcion del Cbirantbodendron demuestran que esta planta de. be reducirse á las Clases.

De Cesalpino. . . I. Arboles cuyo córculo nace del ápice de la semilla.

De Morison. ..... I. Arboles.

De Rayo. . . . . . XXXI. Arboles con fruto seco. De Pablo Herman. XXV. Arboles con fruto seco. De Boerahaye. . XXXIII. Arboles con flores de una pieza.

De Rrvino. . . . . I. Flores regulares de una pieza. Orden X. Cápsulas de cinco celdillas. ( $\mathrm{I}$ )

De Rupro. . . . . I. Flores de una pieza regulares. Orden IX. Cápsulas de cinco celdillas.

De Ludwig. . . . . I. Flores de una pieza regulares. Orden IX. Cápsulas de cinco celdillas.

De Knaucro. . . . . I. Flores de una pieza uniformes. Ordeñ XXXII. Cápsulas de cinco celdillas.

(1). En los seis primeros Sistemas falta órden en qué colocar este Género, y así se podrá ańadir el de Cápsulas leíosas de cinco celdillas como en los siguientes. 
(42.)

De Tounnefort. . XX. Arboles con flores de una pieza. Orden IV. Pistilo que pasa á fruto de muchas celdillas.

De Linneo. . . . XVI. Monadelphia ó Flores con los Estambres reunidos en un cuerpo. Orden V. Pentandria, ó de cinco Estambres.

Orden Natural. . de las Columiferas, ó con los Estambres reunidos en una Colunilla.

\section{LUGAR Y TIEMPO.}

T OS Sabios Autores citados el Dr. Hernandez y el P. Clavigero no se dan por entendidos del lugar ni de la especie de tierra en que vegeta el Arbol de manitas, y es de extrañar que lo omita el primero habiendo sido tan exâcto en la observacion de este punto con casi todos los vegetales que describió en su Historia de plantas de N. E. contentándose con decir de este, que florece al principio del Invierno, y que se mantiene con vigor todo el año, como la mayor parte de los árboles de este continente.

Es muy probable que fuera muy escaso dicho árbol en tiempo del mismo Hernandez, y que se cultivase solo en algunos jardines particulares como una cosa singular y extraordinaria, ó á lo ménos podemos creer que ignoró el sitio en donde vegetaba espontaneamente, porque en este caso no habria dexado de exponerlo.

En el dia no tenemos noticia positiva de que crezca en parte alguna del reyno, sino en Toluca (Ciudad situada á el occidente de México, á unas diez y seis 


\section{(43.)}

leguas de distancia) en la falda de un cerro mus árido y peñascoso, en que solo se crian magueyes y algunas plantas anuas; pero no otra especie de árbol ni de arbusto. Allí se observa un individuo solo de este precioso $\mathrm{y}$ raro vegetal al desabrigo de todas las inclemencias del tiempo, excavado su grueso tronco en la parte inferior, la cima y ramificaciones muy irregulaies, y amenazando ruina su vegetacion por la mucha antiguedad de su exîstencia.

Florece á principios de Invierno, como dice el Dr. Hernandez, y dura su florescencia los meses de Noviembre, Diciembre y Enero. Conserva las hojas todo el año, y nunca se ha podido ver el fruto por el ansia con que buscan de todas partes sus flores, para admirar su extraña y singular estructura, siendo esta la causa de que no pueda verse una flor adelantada en el Arbol, cogiéndolas los Indios y otras personas aun ántes de llegar á rebentarse, aquellos para venderlas, y estas para satisfacer la curiosidad de los que las solici$\tan$.

\section{PROPAGACION.}

Tego que los Señores Botánicos de la Expedicion de este reyno tuvieron noticias de la singular fructificacion del Arbol de las manitas; pasaron á la Ciudad de Toluca á mediados de Diciembre del año de $17^{8} 7$ acompañados de un dibuxante de la misma Expedicion, con el único objeto de observar, describir y dibuxar esta peregrina especie, lo que executaron exâctamente habiendo tenido la satisfaccion de hallar algunas flores abiertas, por las que se sacó al natural el dibuxo de un ramo como se presenta en la estampa, y ademas todo el árbol en compendio. Se informaron de los Indios sobre la propagacion de aquel vegetal por 


\section{(44.)}

semillas ó por estacas, y respondieron supersticiosamente que no queria Dios que hubiera simo un solo $\mathrm{Ar}$ bol de manitas, y que por tanto habicin sido inútiles los esfuerzos de infinitas personas curiosas que habian intentado extenderlo, plantando estacas en diferentes estaciones, y de distintos gruesos en toda especie de tierra, y que habian salido vanas sus esperanzas; añadiendo algunas fábulas ridículas que no son aquí del caso. Los. SS. de la Expedicion hicieron de ellas el desprecio que convenia, y dispusieron se colocase en las primeras divisiones del tronco un gran caxon de tierra en que acodaron varias ramas de diferentes gruesos, y mandaron cubrir con un petate ó estera una rama en que habia algunos botones de flor muy adelantados, con el fin de preservarlos del yelo y recoger sus frutos y semi1las. Encargaron al Señor Corregidor de Toluca y al Gobernador de Indios el cuidado de aquella maniobra, y ofrecieron un premio crecido á el Indio que vivia mas próximo á el árbol, porque regase las ramas acodadas cada tres ó quatro dias, y porque cuidara de las; flores que se dexaban en reserva hasta que estuviesen en sazon los frutos.

Estas prevenciones tuvieron efecto por algunos: dias; pero despues abandonaron el cuidado del caxon, quitaron la cubierta á la rama que se habia reservado, cortaron sus flores, y se habrian frustrado los deseos de nuestros Botánicos, si no hubieran tenido la precaucion de traerse consigo hasta unas veinte y quatro estacas de diferentes gruesos, que arrancaron con bastante corteza de las ramas mayores á que estaban prendidas, colocándolas deśpues en un canasto lleno de tierra de buena calidad, y humedeciéndolas con suficiente canti. dad de agua. 


\section{(45.)}

A su regreso á México las plantaron en mazetas y en barriles, y se mantuvieron frescas por mucho tiempo, rompieron algunas yemas en la mayor parte de las estacas y trasplantaron tres de las mas vigorosas á el Jardin del Real Palacio que sirve hoy de Jardin Botánico, en donde continuaron sin ningun demérito por algunos meses; pero despues se fueron marchitando dos de ellas y perecieron con tocias las demas que habian quedado en la Casa del Director Don Martin de Sesé y Lacasta.

La tercèra y única que pudo lograrse continuó brotando yemas por muchas partes, creciendo algunas hasta la altura de una vara en el primer año: en el segundo fué preciso sacarla de la mazeta en que estaba y trasplantarla en un quadro del Jardin, en donde adquirió mucho vigor, aumentando progresivamente hasta llegar en los ocho años que tiene de vida á la altura de quince varas con tres troncos en que se divide casi hasta su orígen, dos de los quales tienen tres quartas de grueso, y el tercero cinco.

Nuestro Catedrático Don Vicente Cervantes ha procurado en estos años intermedios propagar tan singular y escasa especie, mandando traer de Toluca en diferentes ocasiones hasta ciento y treinta y seis estacas cogidas en la misma estacion y con las mismas precauciones que se observaron con la que está prendida; pero ni estas ni las muchas que ha dado despues la del Jardin que pasan tambien de ciento, han podido prosperar por mas empeño que ha puesto para conseguirlo la destreza é industria del Jardinero mayor Jacinto Lo. pez, ya plantándolas en mazetas y caxones, ya variando las calidades de tierras, y ya últimamente acodando algunas ramas de la misma en embudos grandes de 


\section{(46.)}

hoja de lata llenos de tierra, practicando en ellas quantas diligencias le sugiere el arte de Jardinería, con el objeto de remitir á el Jardin de nuestro Católico Monarca este prodigioso árbol digno de conservarse en los de todos los Soberanos de Furopa; pero nada se ha conseguido hasta el presente dia, y solo se espera que pueda verificarse esto, si llegan á barbar los acodos puestos en el árbol hace ya tres años, ó si se logra que produzca flores y frutos que sazonen las semiIlas. ( $\mathrm{I}$ )

A este efecto mandó el Jardinero mayor despojar el ártol de todas sus hojas á principios del año pasado de 94. cuya operacion se repitió infructuosamente otras quatro veces desde el mes de Septiembre hasta fines de Diciembre del mismo año, y viendo que en todas ocasiones brotaban sus yemas con mayor vigor, hizo sangrar en la Primavera del de 95. una de las gruesas ramas en que está dividido el tronco, haciéndole muchas sajaduras por todos sus lados, y comprimiéndola con fuertes ligaduras en la parte superior con el fin de evitar la demasiada nutricion que le suministra la buena calidad de tierra en que está plantado, lo que ha surtido todo el efecto que se esperaba, pues se hallan cargados algunos ramos superiores de gruesos botones que podrán abrirse en todo el presente año, y sazonarse las semillas á principios del año próxîmo, si se logran los frutos. (2)

(I) Despues de escrito este Discurso supe por el Jardinero mayor que se habian reconocido los acodos de los embudos y que se habia hallado uno de ellos poblado de muchas raices, con lo que se puede ya contar con otro individuo de esta apreciable especie, la que se remitirá con el mayor cuidado en primera ocaston al Real Jardin Botánico de Madrid.

(2) La tardanza que ha ocurrido por varios accidentes en la 


\section{(47.) \\ USOS Y VIRTUDES.}

14 Dr. Hernandez no refiere uso alguno económi-

co ni medicinal del Macpalxocbitl, ni nos avisa si en aquel tiempo hacian los Españoles ó Indios alguna estimacion de sus flores, ántes por el contrario expone en su descripcion que nunca oyó contar de él utilidad alguna médica. No se puede decir lo mismo en el dia, pues ya queda explicado el aprecio que hacen de ellas los curiosos, ni carecen tampoco de uso en la Medicina.

El cocimiento de las hojas y la cataplasma de estas se aplican con buen suceso en las inflamaciones, y para mitigar el dolor de las almorranas, y producen los mismos efectos que las Sidas, Malvaviscos y Malvas, poseyendo como ellas una virtud emoliente, laxânte y madurativa.

Las Flores infundidàs en agua caliente prestan un mucílago abundante parecido al de la Zaragatona, el qual diluido en bastante agua se usa en las inflamaciones de los ojos, y mitiga el dolor de muelas enjuagándose con él.

impresion de este discurso, ha servido para completar la descrip. cion de todo el carácter genérico del Cbirantbodendron, pues habiêndose logrado muchas flores y hasta una docena de frutos, hubo la proporcion de observar completamente sus pericarpios y semillas, las que no obstante de estar bien nutridas y sazonadas no han principiado á vegetar á pesar de haberlas sembrado hace seis meses; pero como,se mantienen enteras y sin la menor alteracion, debe esperarse que puedan hacerlo todavia, no siendo estas las únicas que tardan muchos meses en desplegarse. El Arbol no ha carecido de flores desde que brotaron las primeras, acaso por el mayor abrigo que tienen en este Jardin, y sus frutos han tardado seis y ocho meses en sazonarse. 


\section{"(.48)}

La Raiz es un adstringente poderoso, como dexo dicho, $\mathrm{y}$ así se podria aplicar como tal en muchos casos en que están indicados los adstringentes.

La Madera es muy frágil y blanda, y por tanto no tendria nunca estimacion, aun quando hubiese abundancia de estos árboles.

\section{EXPLICACION DE LA ESTAMPA.}

a. Bráćteas que pueden tenerse por Caliz.

b. Corola abierta que descubre en su fondo las excavaciones del Nectario.

cc. Prominencias que causan exteriormente los Nec. tarios.

d. Vayna del Estílo abierta hasta la division de los Filamentos.

e. f. Gérmen, Estílo y Estigma vistos en todo su tamaño.

\section{g. El Gérmen separado.}

h. El mismo cortado trasversalmente que manifiesta las cinco celdillas.

i. Semillas vistas en el Gérmen.

j. El fruto con la corola ó sea el caliz persistente.

k. El mismo cortado trasversalmente con los cinco loculamentos.

1. Semillas con la glándula cerca de su base. 


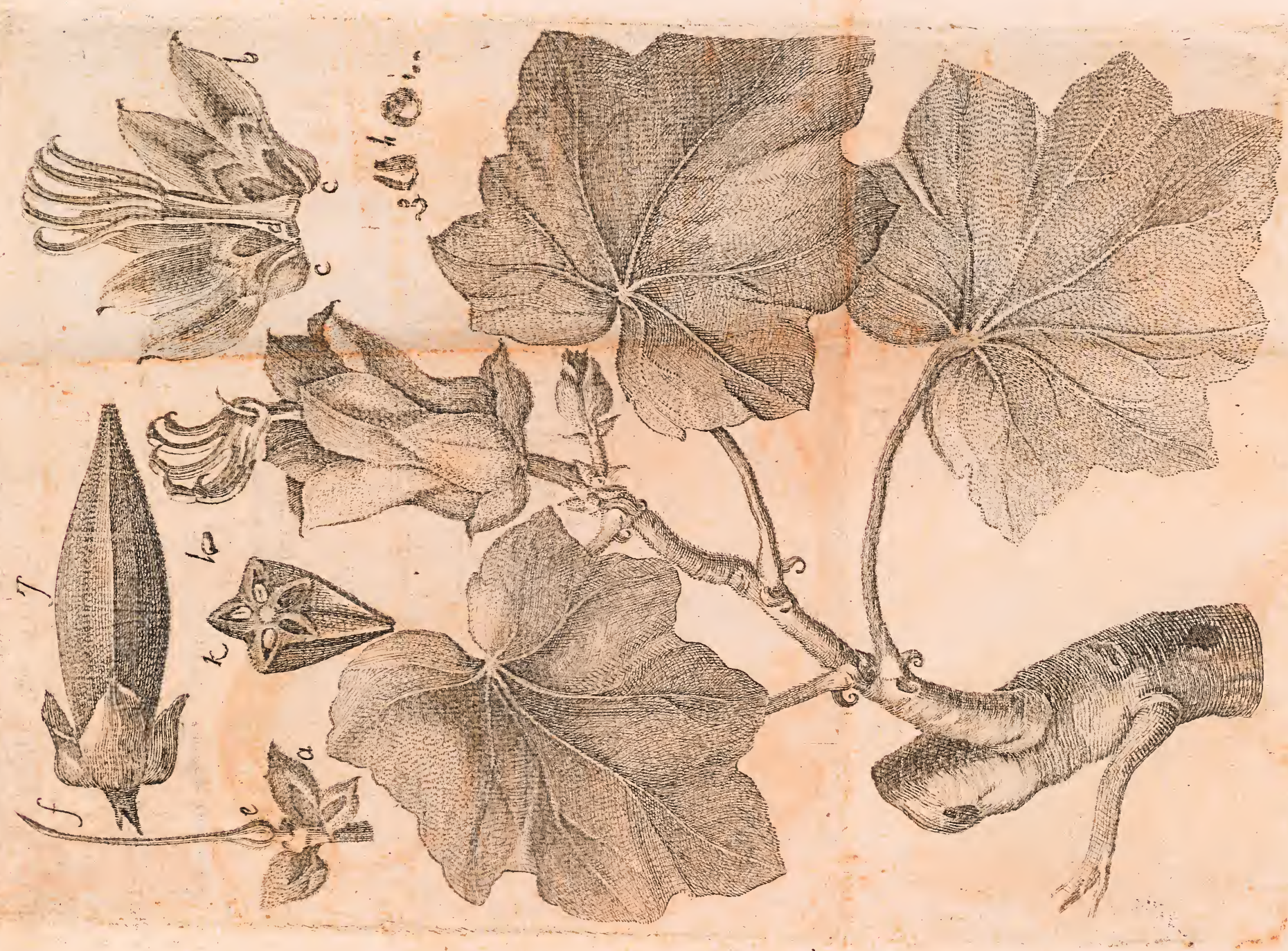


ช. $\therefore$ :

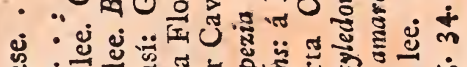

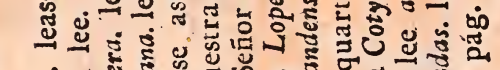

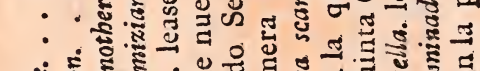
ช

: $\dot{m}$ a

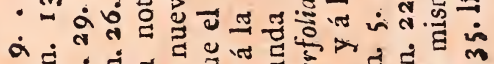

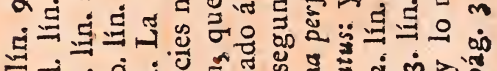
子. os on of o.

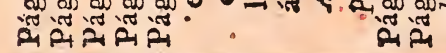

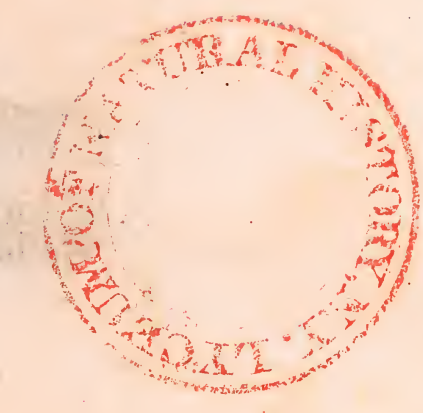



